\title{
Motivational Potential level: Studying the impact on teachers working in school
}

\author{
Vinita Sinha ${ }^{1}$, Pooja Sharma ${ }^{2}$, Sucheta Mandal $^{3}$, Payal Raaj ${ }^{4}$ \\ \{vinita_shinha@scmhrd.edu¹, poojasharma@scmhrd.edu ${ }^{2}$, \\ sucheta_mandal@scmhrd.edu ${ }^{3}$ \}
}

Symbiosis International (Deemed University) - Symbiosis Center for Management and Human Resources ${ }^{1,2,3}$

\begin{abstract}
A nation's growth and development depend on its workforce. Teachers are the building blocks in designing and shaping the nation's workforce from the primary to professional education. Teachers develop the knowledge and skills among the students, which helps a nation to grow and prosper. Thus, teacher's motivation towards their work is an important aspect, as it directly affects the student's future. The study is designed to enhance the understanding about how job characteristics motivate teachers teaching in school. In this study, Job Characteristics has been used to assess the motivational potential level of 40 teachers teaching in school. The results demonstrated that autonomy shows the highest relationship among teachers whereas task significance showed the least. The study implicates that the motivation of the teachers can be increased by enriching certain elements their jobs; it will have a positive impact on the psychological state of a teacher, thus improving their effectiveness.
\end{abstract}

Keywords: job characteristics model, core job characteristics, critical physiological states, motivational potential score.

\section{Introduction}

School education is the foremost and first education in child's education cycle. School education has a long lasting and deep impact on the child's success, emotional wellbeing and character. Thus, it helps in shaping the future citizens of the nation. Therefore, globally school education has been given due important by government and non- government bodies. In India, the government initiative of through 'The Right to Free and Compulsory Education Act, 2009' is a step towards providing free and compulsory education to children from all backgrounds. This initiative is one among many steps taken by government to promote education among children across nation. Initiatives like these are evidence to prove the importance of school education in child's life.

Teachers decipher the philosophy of education, knowledge and skill in a student. Teachers are great influencers in a child's life. They act a guide, mentor, advisor and a friend. In early schooling years the impact of a teacher is very strong on the child's mental and emotional development. They act as a role model for young minds. Therefore, it becomes of utmost importance that the teachers are motivated. A motivated teacher is a key factor in ensuring a healthy classroom and learning behavior. 
Researchers have always been interested in investigating the impact of motivation on the employee's performance. In the past decade, the researches on motivation level of corporate employees have been in ample. But there are very few studies on motivation level of school teachers. Therefore, the present study is conducted to measure the motivational level of teachers by using Job Characteristic Model proposed by Hackman and Oldham [1]. Teacher's motivation is significant as teacher's desire to participate in academic processes, attitude towards work, classroom learning etc. are all influenced by it. A motivated teacher is more committed towards ensuring a rich learning by the students in the class and outside the class.

The concept of 'happy' employees is often baffled by the concept of 'motivated'. These concepts are related but hold a different meaning and have different influence over the employee's performance. Motivation is a state of desire, wherein, an employee is full of energy and have higher commitment and dedication for achieving a goal or target. Myers [2] distinguishes motivation as a desire that influences a person's attitude and conduct. Jones and George [3] elaborated motivation as "psychological forces that determine the direction of person's behavior, a person's level of effort, and a person's level of persistence in the face of obstacles". Sinha [4] explained motivation as a process that defines the individual's intensity, persistence and direction. Motivation is both intrinsic and extrinsic. Intrinsic motivation is the motivation which an individual derives from satisfaction and contentment that an employee achieves from doing a particular task or job. A person internally/ intrinsically motivate is moved to perform out of enjoyment [5]. Extrinsic motivation is the motivation, where the source of motivation lies outside the individual, which may also include technology [6], in such, an individual is motivated to achieve the target or result.

In same context, Richard Hackman and Greg Oldham in [7] developed the job characteristic model; the model states how an organization should design the job so as the employees are internally motivated to do the job. Job characteristic model is a holistic model; it does not demonstrate motivation as short term intervention but describes it as an integral part of job itself. The model states that if an organization wants to have highly motivated employees, it should build a job or design a job which motivates the employees by its composition. Hackman and Oldham [7] stated that a job should have three dimensions namely; core job magnitude, critical psychological states and the work outcomes. The core job magnitude defines them the skill variety, task variety and task significance, autonomy and feedback components of the job. The psychological state defines the meaningfulness of the job, responsibility for the outcome and knowledge of results. The work outcomes define employee performance, turnover and satisfaction of an employee.

Figure 1. demonstrates the Job Characteristic Model [8]

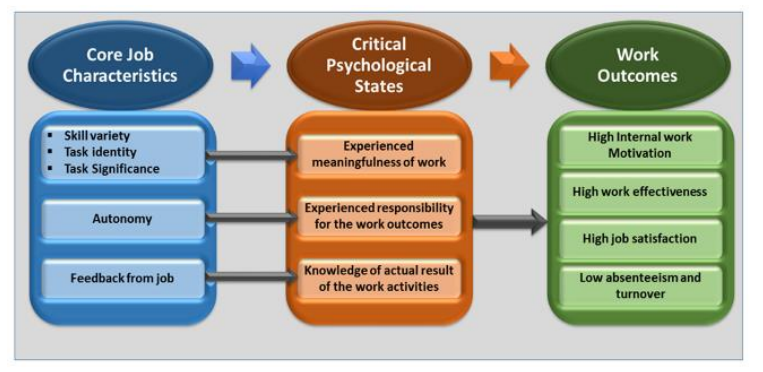


Hackman and Oldham stated that for an individual to be motivated to perform his/ her job, three psychological states must be fulfilled in a given job. The three states being: (a) meaningfulness of the job; (b) responsibility and accountability towards the job and (c) knowledge of the final results. In their research, Hackman \& Oldham [1] concluded that, for an individual to be effective and internally motivated to do a job the three psychological states must be present. Apart from these three psychological states, Hackman and Oldham also proposed five core job characteristics. These job characteristics were namely, task identity, feedback, autonomy, task significance and skill variety. These characteristics were related to job. These characteristics were measurable. The ever-changing characteristic of the jobs, which affect the three psychological states, affects the motivation level of an individual.

\subsection{Core job characteristics}

Hackman and Oldham [7] defined core job distinctiveness with the five dimensions that is present in a job. These dimensions propose the five core characters of a job which affects the internal work motivation of an individual. Listed below are the five dimensions of motivational potential:

1.1.1 Skill Variety: Skill variety is defined as the number of different skills a job holder is able to use in a given job. It demarcates the various skills and talents an employee is able to use in an job. Hackman \& Oldham [7], [9] defined skill variety as the level of challenging skills/ talents/ abilities required to perform a job by an individual. The job with high variety of skills gives the employee the opportunity to exploit several different competencies (practical, managerial \& social). High skill variety job may be a English teacher teaching her students as well as giving demonstration to the new teachers "how to teach the class in an innovative ways" which requires presentation skills.

1.1.2 Task Identity: Task identity is defined as the control a job holder has over completing a given job from beginning to end. It defines the power/ controls an employee's exercises over completing a task from the start to the end. Hadi \& Adil [10] defined task identity as individual's requirement to complete all the tasks from the beginning to end of the production process. An individual will have higher task identity when he/ she works on a product or project from the start to the end and are able to see tangible outcomes. In schoolteacher context, the power to designing different evaluations and conduct them will give them higher task identity.

1.1.3 Task Significance: Task significance is defined as the importance a given job holds in making an impact on a greater cause. It distinct the impact a job is creating on the organization or society in general. Morris and Venkatesh [11] defined task significance as the extent of impact a job has over the organization or society at large. An important task can be for example, a teacher at the school who can see how her ways of things doing, has a direct impact on student's learning.

1.1.4 Autonomy: Autonomy is defined as the independence a job holder enjoys completing the job. Autonomy demarcates the degree of freedom an employee has over scheduling and completing his/ her job. Mukul et al. [12] defined autonomy as the altitude of freedom, liberty and discretion an individual has to plan, schedule and complete his/ her task. Individuals with more autonomy are more internally motivated than individuals who are given less autonomy. In context of schoolteacher, the autonomy to schedule his/ her teaching sessions and evaluations will ensure higher autonomy in the job and vise- versa. 
1.1.5 Feedback: Feedback is defined as the review of performance a job holder gets for his/ her job. Feedback clearly states how an employee is performing his/ her job and how it can be improved. Lunenburg [13] defined the job feedback as the altitude of direction, information and assessment provided to an individual on the job performed by him/ her. Feedback can either be positive or can be negative, but the best approach is to balance the both the positive and negative appropriately. A job with high feedback is when the teacher gets immediate feedback from parents after the result is out. A low feedback job is of cleaner from school, who rarely gets feedback from students about the standard of cleaning.

\subsection{Critical Psychological States}

Hackman and Oldham [7] proposed a crucial factor of psychological state to establish a link between the internal work motivation and job characteristics of an individual. Internal work motivation is attained from the work which establishes the three crucial psychological states; namely knowledge of results, meaningfulness of the job and responsibility of outcomes. Hackman and Oldham [1] suggested that the task identity, skill variety and task significance contribute to the individual finding meaningfulness in the job, whereas autonomy affects the responsibility of outcome state and lastly feedback influences the knowledge of the results for an individual.

Responsibility for work outcomes is the degree to which a person is accountable for his outcomes of the work. As stated by researchers Russon and Brown [14] if an individual perceives that the quality of the completed work is more dependent on external factors than his/ her efforts and initiatives, this feeling leads to dissatisfaction in an individual. Hackman and Oldham [9], in the job characteristics model, proposed 'autonomy' to be an important factor that affects the employee experience of responsibility of outcome. They stated that, with the increase in autonomy, an individual feel more responsible for success or failure of the job.

Knowledge of results is the degree to which an employee is performing in his/ her job; it may be influenced by feedback the employee receives for his/ her job performance. According to Thapisa [15] an open feedback facilitates the knowledge of work-related results. Hackman and Oldham [9], in the job characteristics model, proposed 'feedback' to be a crucial factor that influences the knowledge of outcome of results for an employee in a job.

Meaningfulness of the work is the degree to which an employee feels his/ her job is significant. According to Russon and Brown [14], if an employee feels his/ her job is not significant then the employee is not internally motivated to work, even if the employee gets ample feedback or is individually accountable for the work and outcomes. Hackman and Oldham [9], in the job characteristics model, proposed a combination of task significance, skill variety and task identity leads to an experience of a more meaningful job.

The job characteristics model suggested that, when an employee is able to achieve all the three psychological states, this leads to his/ her higher internal work motivation, higher job performance, increased satisfaction and lower absenteeism, turnover and deviant workplace behavior. 


\subsection{Work outcomes}

The five job dimensions prompting three psychological states lead to work outcomes which are internal motivation, job satisfaction, and work effectiveness.

Internal work motivation details the level of self- motivation an employee experiences to do a job effectively. It means a sense of internal feeling of positivity while doing a job good and vises a versa, a sense of negative feeling while doing a job badly [1].

Job satisfaction details the multidimensional psychological response to one's job [16]. Job satisfaction has the both cognitive and affective components. Job satisfaction can be understood as an individual's experience of his/ her job expectations in line with job outcomes. Locke [17] described job satisfaction as "a pleasurable or positive emotional state resulting from the appraisal of one's job or job experiences".

Work effectiveness details the standard of the outcome in form of goods or services. The U.S. Merit Systems Protection Board [18] suggested that a decent work design can increase the work effectiveness as job characteristics influence the motivation level of employees.

\subsection{Motivational Potential Score (MPS)}

Motivational Potential Score (MPS) combines all the five job characteristics in a single index and measure the motivational potential of a job. To measure work outcomes according to individual job characteristic, Hackman and Oldham [7] proposed the Motivational Potential Score (MPS). MPS recommend that by assessing the all the components of core job dimensions and crucial psychological states, the potential motivation score of an individual can be calculated. This being a multiplication model suggests that if the score of one component is low the overall MPS score will be adversely affected. MPS is a single index that combines the five core characteristics which indicates the potential of the job to support internal motivation [19].

Hackman and Oldham [7] developed the below equation to determine individual employee's MPS score as represented in Figure 2.

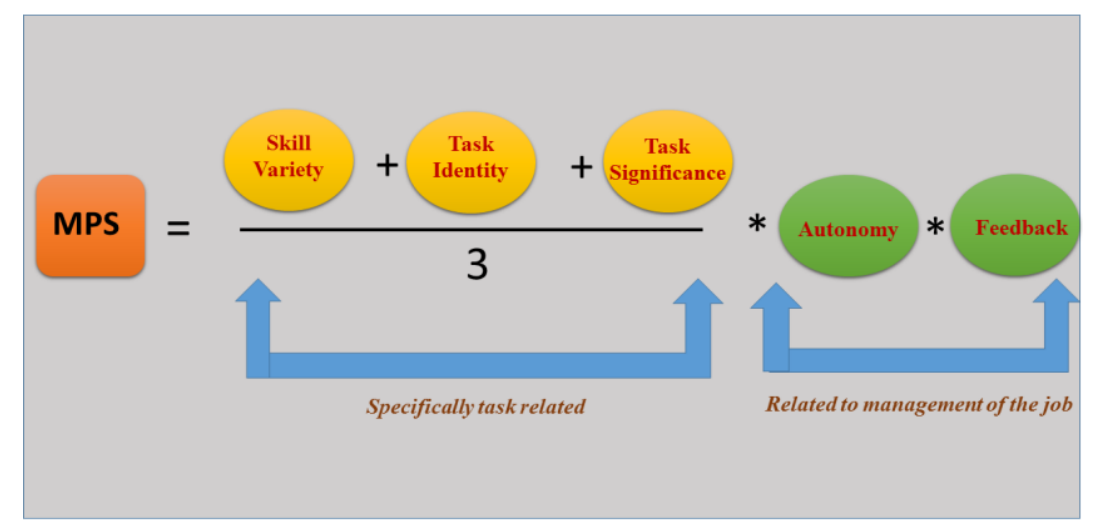

Fig. 2. Motivational Potential Score model. 
This model suggests that if the motivational potential of the job is low, the outcome driven from the same will also be less and an employee's sense will not be influenced by how effectively the work was completed. Whereas, if the MPS score of a job is high, the outcome drive will also be high, and an employee's feeling will also be positive. Thus, the three dimensions of the Job Characteristic Model; namely, Core Job Characteristics, Critical Psychological States and Work Outcomes are interlinked and have mutual dependency. The lower score or absence of one factor influences the overall motivation score adversely.

\section{Literature Review}

The conception of employee estrangement from work and organizational productivity is becoming more and more important in today's competitive world, where a motivated and engaged employee is a competitive advantage. Thus, the organizations are redesigning their work as a part of organizational change strategy to ensure higher level of employee motivation. Ample amount of research has been conducted on employee attitude and behavior in the last decade. A well-designed job has an affirmative influence on work and performances of an employee [20], [21]. This was partly agreed by other researchers [22], [23]. Criticism of this model is largely focused on the measurement of the characteristics based on individual's perceptions of job incumbents, and thus supposedly lacking in objectivity [24], [25]. By providing skill variety to job will decrease the boredom and thus increase the satisfaction and motivation of employees. When an employee work for small part of the whole task, they don't feel any sense of responsibility and meaningfulness of work, since they cannot identify finished product from their effort. But when this task is broadened to produce the whole product, then task identity is established. Task significance develops a sense of meaningfulness and worthy fullness towards the job in an individual. If the employee knows that others are dependent or impacted by his/her work, motivation to do the job will increase. Jobs which score high on autonomy develop a sense of accountability and satisfaction among the employees. Feedback at work means acquiring knowledge of work. The feedback can be from supervisor, manager, clients or from work itself. The mere incidence of feedback is not sufficient enough to motivate an employee, the way it is given is equally or more significant. Thus, job design/redesign which is understood and agreed upon by both employee and employer is of great importance in ensuring work motivation. Thus, it is important to design/ redesign the jobs which reduce the stress of an individual and increase the work motivation, satisfaction, commitment and performance of an individual. Many studies showed that job characteristics are prime factors of work-related outcomes as well as performance of individual and organization.

Job satisfaction and job characteristics among call center workers where the employee turnover rates are found to be significantly higher than most of other job positions revealed an existence of a strong correlation between Motivating Potential Score and job satisfaction [26]. As well as among the job characteristics, feedback showed greatest relationship to job satisfaction among call canter workers.

Lawrence [27] conducted a study on application of Hackman and Oldham's Job characteristics Model to Community Music school faculty in United States. The sample consists of 437 faculties who responded to the research questions addressed to core job characteristics and critical psychological states. The findings showed that there is a positive correlation between Job characteristic model and job satisfaction. It also indicated that autonomy shows the strongest relation among other job characteristics. 
Research also indicates that by designing the job to enhance job content which in turn makes them more challenging and interesting, increases motivation of employees [13]. He stated that elevating certain parts of jobs positively influences the psychological state of the job thus ultimately enhancing the work effectiveness of the employees.

Grant [28] studied the impact of task significance on job performance. In his study of lifeguards, he found that when an individual feels responsible for the overall outcome and not just a part of outcome and perceives their work to be of great significance, then an individual put great amount of efforts in the work and drives a sense of pride from the work.

Shantz et al. [29] in their study found a positive relationship among four of the job dimension namely; skill variety, autonomy, significance and feedback. Wherein, the skill variety demonstrated the strongest relationship. The sample consists of 283 employees from UK based consultancy and construction firm and their results revealed that employees holding the job that offers high level of core job characteristics namely; task variety, feedback, task significance and autonomy, are more engaged. They get better performance rating from managers and are less likely to behave in "deviant" ways.

Anjum [30] investigated the relationship between job characteristics and job satisfaction among the banking employees. In his study of 100 banking employees from different banks, he revealed task identity to be affirmative and strong predictor of job satisfaction. The study also highlighted that the job characteristics and both intrinsic and extrinsic motivation have a influence on job satisfaction of an employee.

A meta-analysis by Fried and Ferries [31] supported the mediating role of the critical psychological states on the relationship between job characteristics and psychological outcomes. Their study reflected that core job dimensions had a high correlation with psychological states, although, the psychological states showed significantly stronger correlations with the psychological outcomes rather than the core job characteristics.

Motivation plays a significant role for teachers to achieve targets competently. Motivation of teachers is imperative since it has direct impact on the increasing skill and knowledge of a teacher, consequently affecting the students' performance [32]. A lack of motivation within teachers, reduces the capability of the teacher and hence, a deterioration of the education system. Most studies have focused on the motivation, external conditions and performance of a teacher [33], [34], [35], [36], [37].

Few studies are dedicated to applying the job characteristics model to school teachers and the applicability with regards to the quality of job and the required changes to make teaching an intrinsically motivated work. One such research based on this model generated results which confirms the utility of the model and the tool (Job Diagnostic Survey); promoting the relationship between job characteristics and psychological states [38]. Firstly, the Job Characteristic Model has been chosen for the present study to replicate the relationship proposed by Hackman and Oldham [1], and scrutinize the different components presented in the model, for schoolteachers, which is less attempted. Secondly, unlike in the past, job character was a one-time enterprise, designed from top to down, and applied universally to all comparable jobs. However, it is progressively becoming more changeable, initiated from bottom to up, and is applied distinctively, sometimes to even identical jobs [39]. Thus, job characteristics model is applicable and judicious aspect of context to be investigated. 


\section{Methodology}

\subsection{Objective}

The following are the objectives of the current study:

- To analyze the components (skill variety, task identity, task significance, autonomy, feedback) of motivational potential level among teachers working in the school.

- To analyze the critical psychological states (meaningfulness of work, responsibility of work and knowledge of the result) among the teachers.

- To establish the correlation between:

○ The three job dimensions (skill variety, task identity, task significance) and meaningfulness of work.

○ Autonomy and responsibility of work outcome.

- Feedback and knowledge of actual result.

\subsection{Tool}

The primary data collection instrument used is Job Diagnostic Survey, which is the principle assessment tool developed by Hackman and Oldham [8] for purpose of measuring the overall motivational potential of job in terms of core job characteristics. The instrument includes items appearing as questions or statements, and asks participants to respond in terms of their own job. The instrument includes questions or statements measured through 7 point scale $(1=$ low, $7=$ high), and ask the participants to respond in terms of their job according to their perception. Items are arranged randomly from each dimension throughout the instrument. However, JDS is unable to assess the level of employee knowledge and skill and employee work effectiveness.

\subsection{Scoring}

The questionnaire investigated the motivational potential score (MPS) and the relationship between different facets of job characteristics model of the teachers. There were in total 45 statements in the questionnaire. The whole of the questionnaire was divided into 4 sections. First sections comprise of 6 statements, second section had 14 statements, both first and second sections comprises of questions regarding participants job profile. Third section had 15 statements, which were focusing on participants feelings towards his/ her job. Lastly, the fourth section had 10 statements which were focusing on how and what other people in the same organization think about their job which is almost similar to job the individual holds. A total of 45 questionnaires were circulated, out of which 40 completely filled questionnaires were received, thus were used for the study.

\section{Data Analysis}

Table 1 indicates the result of analysis by the means of minimum, maximum and standards deviations. The results were calculated for each of the facet of job characteristics model i.e., 
core job characteristics and critical physiological states. Motivational potential score (MPS) was calculated based on the formula mentioned previously in the paper.

Table 1. Statistical Analysis of Questionnaire Results. N = Total Number of employees; N1= Number of employees who scored below average; N2 = Number of employees who scored above average

\begin{tabular}{|c|c|c|c|c|c|c|c|c|}
\hline Categories & $N$ & Minimum & N1 & Maximum & N2 & Mean & $\begin{array}{l}\text { Standard } \\
\text { Deviation }\end{array}$ \\
\hline \multicolumn{7}{|c|}{ Core Job Characteristics } \\
\hline Skill variety & 40 & 3 & 19 & 6.6 & 21 & 5.11 & 0.784 \\
\hline Task Identity & 40 & 3.6 & 19 & 7 & 21 & 5.33 & 0.894 \\
\hline Task Significance & 40 & 3 & 23 & 7 & 17 & 5.64 & 0.931 \\
\hline Autonomy & 40 & 3.3 & 17 & 6.6 & 23 & 5.25 & 0.918 \\
\hline Feedback & 40 & 3.3 & 21 & 6.6 & 19 & 5.24 & 0.940 \\
\hline MPS & 40 & 49.89 & 19 & 263.27 & 21 & 148.12 & 50.854 \\
\hline Meaningfulness of work & 40 & 4.25 & 19 & 6.75 & 21 & 5.71 & 0.563 \\
\hline Responsibility for outcome & 40 & 3.33 & 18 & 6.66 & 22 & 5.32 & 0.790 \\
\hline Knowledge of actual result & 40 & 3.5 & 19 & 6.5 & 21 & 5.08 & 0.722 \\
\hline
\end{tabular}

\subsection{Core Job Characteristics}

The results from the analysis clearly state that, 21 employees out of 40 employees have scored more than the average score on task identity. Thus, fifty two percent of employees suggested having variety of skills in their given job which allows them to use varied skills to be used in their job. Employees with low scores reflect that their jobs can be enriched by adding various skills and competencies according to the skills and competencies of the teachers.

On task identity, more than half of the employees who were part of survey experiences reflected a sense of identity with jobs they do on day to day basis. At the end of the day, the learning that happens to children because of their teaching is visible to them which in turn give them meaning to their job and hence internally motivate them. The rest of employees who score less on task identity experience little contribution to the work they do.

On the facet of task significance, 23 teachers out of 40 teachers reported to believe that their job has a significant impact on organization in particular and society in general. Though, the remaining teachers felt that the work they do gives them higher sense of satisfaction and contentment.

On the autonomy facet, 23 teachers out of total of 40 teachers felt that they have the autonomy and freedom to decide how they intend to perform their jobs. However, the remaining 19 teachers felt they have low autonomy and felt less intrinsically motivated towards their jobs. This lack to autonomy can be attributed to either the lack of skills in the teachers to perform the task independently and completely or the management practice of allowing low autonomy in spite of the skills and talents.

On the facet of feedback, 21 teachers out of 40 felt the lack of proper and timely feedback on their work-related duties. However, 19 teachers stated that they receive proper feedback from all the stakeholders on different aspects of their job. They also suggested that the regular and 
timely feedback has helped them in making them more effective and efficient in doing theor jobs.

\subsection{Critical Psychological State}

On account of meaningfulness of the work, 19 teachers out of 40 scores below average. Thereby, indicating that about forty seven percent of teachers feel their work to be of low to no importance. They don't feel internally motivated towards their job. On account of responsibility towards the work outcome dimension, 20 teachers out of 40 felt responsibility towards the work outcome. Thus, fifty percent of the teachers felt that they are responsible towards the outcome of the work. They felt their work to be of great importance. The result on knowledge of result dimension, 21 teachers out of 40 felt they were receiving a proper information on the results of their work. They believed, they were given timely and proper information on how the performance was and on how the performance can be enhanced.

Figure 3 shows the graphical representation of motivational potential score of 40 teachers. The average score is 148 , out of 343 , which reflects the overall potential of job to foster the internal work motivation on the part of teacher. For the employees who have scored low in this regard, to increase their internal motivation their work has to be redesigned according to the variables discussed in the job characteristic model.

Fig. 3. Motivational Potential Score.

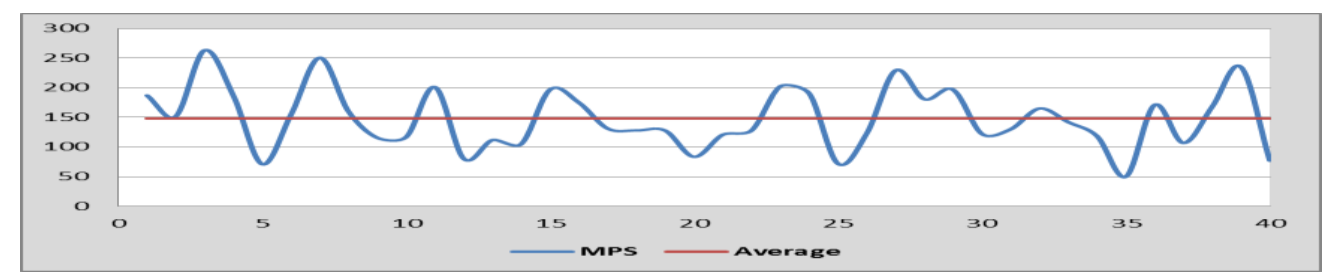

\subsection{Correlation}

The correlation value(r), range from $-1<r<+1$. If $r$ is close to +1 indicates positive relation between $\mathrm{x}$ and $\mathrm{y}$ variables i.e. as values for $\mathrm{x}$ increases, values for $\mathrm{y}$ also increases. If $\mathrm{r}$ is close to -1 indicates negative relation between $\mathrm{x}$ and $\mathrm{y}$ variables i.e. as values for $\mathrm{x}$ increases, values for y decreases. Generally correlation which is greater than 0.8 is described as "strong" one, whereas a correlation less than 0.5 are generally described as "weak" one.

Figure 4 shows the graphical representation of correlation between average of three job dimensions (skill variety, task identity and task significance) and meaningfulness of work. The correlation score is 0.694 . 
Fig. 4. Correlation between Average of three job dimensions and Meaningfulness of work.

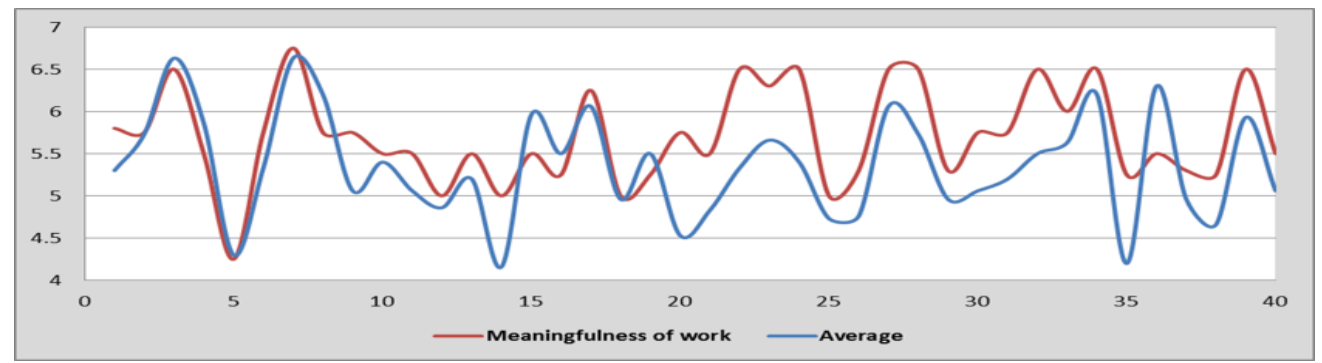

This indicates that though the correlation between two variables exists but it's not a strong one. The graph clearly indicates that there exists deviation between two variables. The reason may be that the individual doesn't feel that their task is meaningful and important. This feeling can either be due to the lack of skill variety or task identity or task significance in the work they do.

Fig. 5. Correlation between feedback and knowledge.

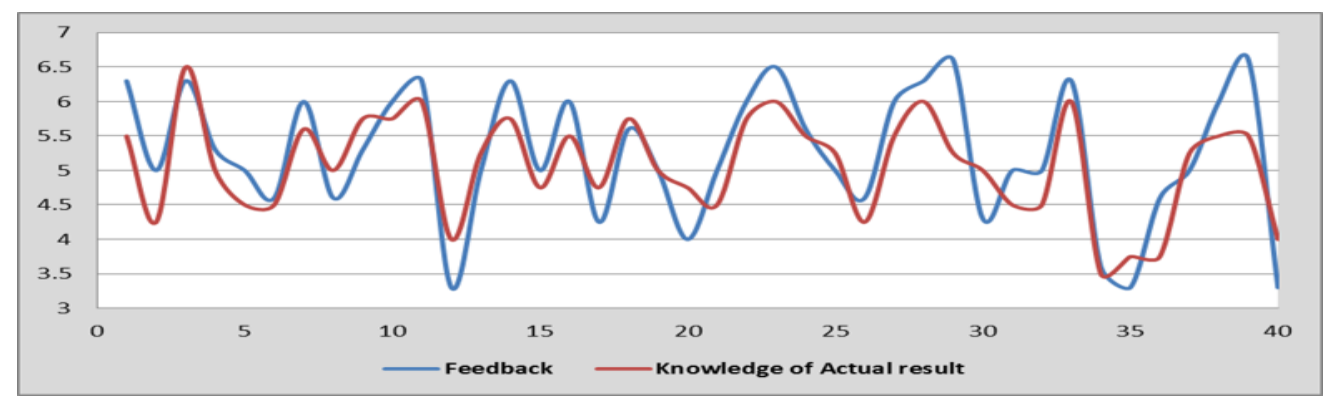

Figure 5 shows the graphical representation of correlation between feedback and knowledge. The score in this regard is 0.848 which implies that there exists a strong correlation between two variables. It shows that the feedback provided on regular basis is the reflection of actual work done by the individual. Though from the graph it's clear that slight deviation between the variables also exist which indicates that few employees feel that the feedback given to them are not as per their performance.

Fig. 6. Correlation between autonomy and responsibility for work outcome.

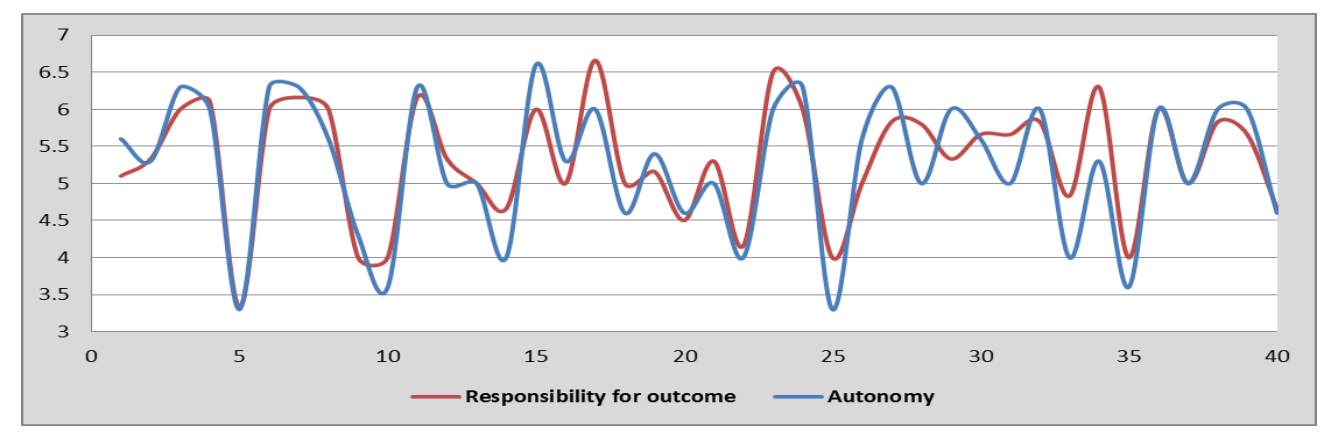


Figure 6 shows the graphical representation of correlation between autonomy and responsibility for work outcome. The score in this regard is 0.883 which indicates a strong relation between the variables. It implies that by giving autonomy to the employees they feel sense of responsibility for the work outcome. It can also be observed that with a decrease in autonomy for work, the sense of responsibility for outcome also decreases and vice versa. Additionally, the graph also indicates that slight deviation exist which may be due to the individuals' lack of skills to perform the work independently or management's reluctance in giving them autonomy to do the work even though they possess the requisite skill set to perform the work.

\subsection{Key Findings}

The average motivational potential score among teachers was found to be 148.02. This result indicates that the employees scoring above average in motivational potential score are internally motivated while those who scored low are comparatively less internally motivated. Their lack of motivation may appear through the behavior of absenteeism or low work effectiveness in near future.

The correlation between average of skill variety, task identity, task significance and meaningfulness of work was found to be 0.694. This score does not show a strong positive correlation; however it may indicate that most of the employees don't feel their work is meaningful. This may be due to lack of either skill variety, task significance or task identity in their work they do.

The correlation between feedback and knowledge of actual result was found to be 0.848 which shows a strong correlation between both the variables. It suggests that the feedback provided on regular basis is the reflection of actual work done by the individual

The correlation between autonomy and responsibility of work outcome is found to be 0.883 which indicates that there exists a strong positive correlation between them. It implies that by giving autonomy to the employees a sense of responsibility for the work outcome is generated within the teachers.

The findings revealed that most of the participants felt job "autonomy" to be a significant identifier for motivational potential of a job, while task significance showed the least relationship amongst them. In case of critical psychological states, most of the participants showed they are "responsible for the work outcome", and hence they showed more accountability and responsibility for the work they do. Furthermore, "knowledge of result" showed the least relationship which indicates a possibility of lack of awareness the effectiveness of the work done by the individuals.

\section{$5 \quad$ Recommendations}

The study revealed that the job design based on Hackman and Oldham's job characteristics theory can significantly help the schools. The results indicate that the use of the job characteristics model, while designing the job itself can significantly improve the internal motivation level of the teachers. The use of an empirically tested model which designing the job will definitely ensure a more robust job design which will definitely help the schools in dealing with the issue of demotivated teachers. The study suggests that schools can increase the 
performance of the teachers by providing them regular feedback. According to the study, regular feedback from the management is very crucial for enhancing the performance level of the schoolteachers, this will have an impact on the level of teacher's engagement in teaching and non- teaching activities. Feedback helps the teachers in knowing the actual results of their activities which will have a positive impact on their motivational level. Training or up-skilling is of significant importance in this era of fast evolving school education. This study also suggests that by providing adequate and timely training to the teachers based on their skill set and job content. This will ensure the school management of more competent and motivated teaching staff in the school.

\section{Conclusion}

The present study was an attempt to assess the motivation of schoolteachers using "Job Characteristic model" designed by Hackman and Oldham. On the basis of above conducted analysis, it can be concluded that a job high in motivating potential must be high on at least one of the three job dimensions (skill variety, task significance, task identity) which indicate that the employee feels meaningfulness in his/her work.

A job high in motivating potential must be high on autonomy which indicates that employee feel responsible for his/her work outcome. Additionally, a job high in motivating potential must be high on feedback which indicates that employee is aware how effective he/she performs in his work.

\section{Limitation}

The findings of the current study are based on a sample size of 40 teachers, to make the results of the study more reliable and generalizable; a study at a wider scale needs to be conducted. Then only the results can be applied and generalized. Secondly, this study is focusing only on schoolteachers, the study can be extended to the nurses, non- teaching staff at schools, and police staff for understanding their motivation levels. Lastly, the current study does not take into account the management perspective of motivation level of teachers, in the future study researchers can also try to investigate the school management point of view regarding motivation level of schoolteachers.

\section{References}

[1] Hackman, J. Richard, and Greg R. Oldham. "Development of the job diagnostic survey." Journal of Applied psychology 60, no. 2 (1975): 159.

[2] Myers, David G. Psychology in everyday life. Macmillan, 2011.

[3] Jones, Gareth R., Jennifer M. George, and Charles WL Hill. Contemporary management. Irwin/McGraw-Hill, 2000.

[4] Sinha, Vinita, Ashy Abraham, Bhavya Bhaskarna, Kevin Xavier, and Karthik Kariat. "Role efficacy: Studying the impact on employee engagement, employee motivation and attrition." 
International Journal of Human Capital and Information Technology Professionals (IJHCITP) 5, no. 4 (2014): 35-54.

[5] Ryan, Richard M., and Edward L. Deci. "Intrinsic and extrinsic motivations: Classic definitions and new directions." Contemporary educational psychology 25, no. 1 (2000): 54-67.

[6] Gómez-Carmona, Oihane. " Towards healthy office environments: A worker-centric internet of things approach.” European Alliance for Innovation 4, no. 13 (2018).

[7] Hackman, J. Richard, and Greg R. Oldham. "Motivation through the design of work: Test of a theory." Organizational behavior and human performance 16, no. 2 (1976): 250-279.

[8] Hackman, J. Richard, and Greg R. Oldham. "The Job Diagnostic Survey: An instrument for the diagnosis of jobs and the evaluation of job redesign projects." (1974).

[9] Hackman, J. Richard, and Greg R. Oldham. "Work redesign (Vol. 72)." Reading: AddisonWesley (1980).

[10] Hadi, Rabia, and Adnan Adil. "Job characteristics as predictors of work motivation and job satisfaction of bank employees." Journal of the Indian Academy of Applied Psychology 36, no. 2 (2010): 294-299.

[11] Morris, Michael G., and Viswanath Venkatesh. "Job characteristics and job satisfaction: understanding the role of enterprise resource planning system implementation." Mis Quarterly (2010): 143-161.

[12] Mukul, Abu Zafar Ahmed, Shah Johir Rayhan, Fazlul Hoque, and Faijul Islam. "Job characteristics model of Hackman and Oldham in garment sector in Bangladesh: a case study at Savar area in Dhaka district." International Journal of Economics, Finance and Management Sciences 1, no. 4 (2013): 188-195.

[13] Lunenburg, Fred C. "Motivating by enriching jobs to make them more interesting and challenging." International journal of management, business, and administration 15, no. 1 (2011): 1-11.

[14] Russon, C. and Brown, A. (2006). Job design for evaluation. Evaluation Capacity Development Group.

[15] Thapisa, Amos PN. "The meaningfulness of work: improving the quality of work life through job enrichment." PhD diss., University of Sheffield, 1989.

[16] Judge, Timothy A., Ronald F. Piccolo, Nathan P. Podsakoff, John C. Shaw, and Bruce L. Rich. "The relationship between pay and job satisfaction: A meta-analysis of the literature." Journal of Vocational Behavior 77, no. 2 (2010): 157-167.

[17] Locke, Edwin A., and Marvin D. Dunnette. "Handbook of industrial and organizational psychology." The nature and causes of job satisfaction (1976): 1297-1349.

[18] The U.S. Merit Systems Protection Board. (2012). Federal employee engagement: The Motivating potential of job characteristics and rewards. A report to the president and the congress of the United State.

[19] Oyler, Jennifer D. "Core Self-Evaluations and Job Satisfaction: The Role of Organizational and Community Embeddedness." PhD diss., Virginia Tech, 2007. 
[20] Fox, Shaul, and Gerald Feldman. "Attention state and critical psychological states as mediators between job dimensions and job outcomes." Human Relations 41, no. 3 (1988): 229245 .

[21] Kiggundu, Moses N. "An empirical test of the theory of job design using multiple job ratings." Human Relations 33, no. 5 (1980): 339-351.

[22] Evans, Martin G., Moses N. Kiggundu, and Robert J. House. "A partial test and extension of the job characteristics model of motivation." Organizational Behavior and Human Performance24, no. 3 (1979): 354-381.

[23] Hogan, Eileen A., and Daniel A. Martell. "A confirmatory structural equations analysis of the job characteristics model." Organizational Behavior and Human Decision Processes 39, no. 2 (1987): 242-263.

[24] O'Reilly, Charles A., and David F. Caldwell. "Informational influence as a determinant of perceived task characteristics and job satisfaction." Journal of Applied Psychology 64, no. 2 (1979): 157.

[25] White, Sam E., and Terence R. Mitchell. "Job enrichment versus social cues: A comparison and competitive test." Journal of Applied Psychology 64, no. 1 (1979): 1.

[26] Leblanc, Carly M. "The Relationships Between Job Characteristics and Job Satisfaction Among Call Center Workers." (2013).

[27] Lawrence, Robert M. "The application of Hackman and Oldham's Job Characteristic Model to perceptions community music school faculty have towards their job (JR Hackman, GR Oldham)." (2003): 0101-0101.

[28] Grant, Adam M. "The significance of task significance: Job performance effects, relational mechanisms, and boundary conditions." Journal of applied psychology 93, no. 1 (2008): 108.

[39] Shantz, Amanda, Kerstin Alfes, Catherine Truss, and Emma Soane. "The role of employee engagement in the relationship between job design and task performance, citizenship and deviant behaviours." The International Journal of Human Resource Management 24, no. 13 (2013): 2608-2627.

[30] Anjum, Zaman. "Job Characteristics Model and Job Satisfaction." International Journal of Education and Research2, no. 11 (2014).

[31] Fried, Yitzhak, and Gerald R. Ferris. "The validity of the job characteristics model: A review and meta-analysis." Personnel psychology 40, no. 2 (1987): 287-322.

[32] Mustafa, M. Nur, and Norasmah Othman. "The effect of work motivation on teacher's work performance in pekanbaru senior high schools, Riau Province, Indonesia." Sosiohumanika 3, no. 2 (2010).

[33] Davidson, Euan. "The pivotal role of teacher motivation in Tanzanian education." In The educational forum, vol. 71, no. 2, pp. 157-166. Taylor \& Francis Group, 2007.

[34] Dessler, Gary. A framework for human resource management. Pearson Education India, 2006. 
[35] Inayatullah, Atiya, and Palwasha Jehangir. "Teacher's job performance: The role of motivation." Abasyn Journal of Social Sciences 5, no. 2 (2012): 78-99.

[36] Kadzamira, ESME CHIPO. "Teacher motivation and incentives in Malawi." Zomba: Centre for Education Research and Training (2006): 1-26.

[37] Nadeem, Mohammad, Musarrat Shaheen Rana, Abdul Hameed Lone, Saira Maqbool, Khansa Naz, and Ali Akhtar. "Teacher's Competencies And Factors Affecting The Performance Of Female Teachers In Bahawalpur (Southern Punjab) Pakistan." International Journal of Business and Social Science 2, no. 19 (2011).

[38] Barnabé, Clermont, and Mildred Burns. "Teachers' job characteristics and motivation." Educational Research 36, no. 2 (1994): 171-185.

[39] Hornung, Severin, Denise M. Rousseau, Jürgen Glaser, Peter Angerer, and Matthias Weigl. "Beyond top-down and bottom-up work redesign: Customizing job content through idiosyncratic deals." Journal of Organizational Behavior 31, no. 2-3 (2010): 187-215. 